\title{
Partner With Parents
}

\author{
JOYCE A. BRANDES
}

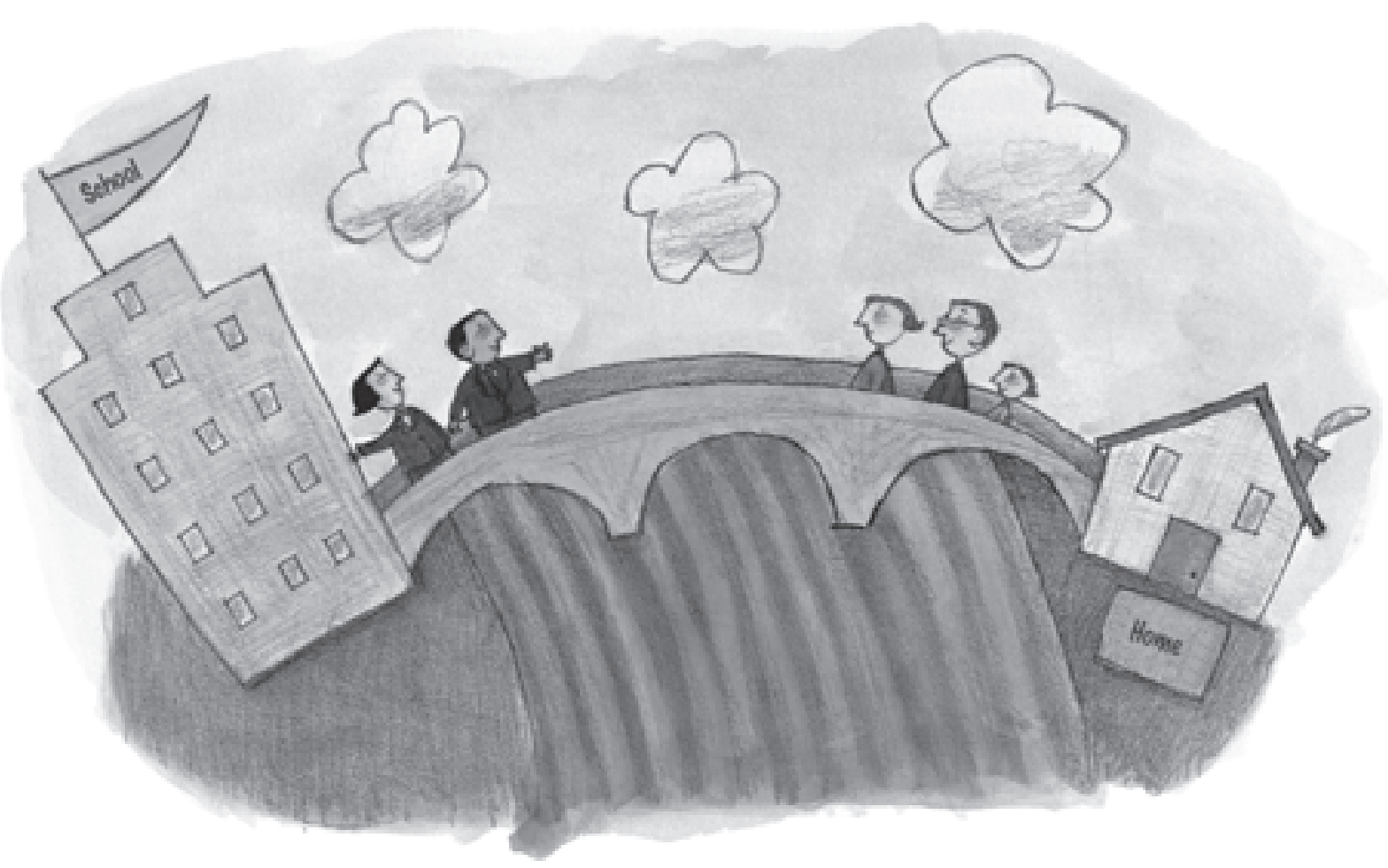

Keeping parents involved in their child's education is of primary importance (Lucyshyn, Dunlap, \& Albin, 2002; Shonkoff \& Phillips, 2000; Webster-Stratton, 1998) and can be effectively accomplished through meaningful communication. The following recommendations are not meant to be an all-inclusive listing of how to foster effective communication with parents but instead serve as a guide to promote healthy relationships based on respect.

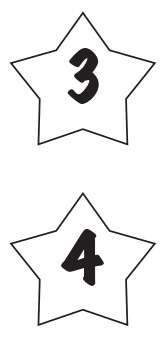

Take notes openly while conversing with

parents. Check for accuracy with parents before the conclusion of the exchange.

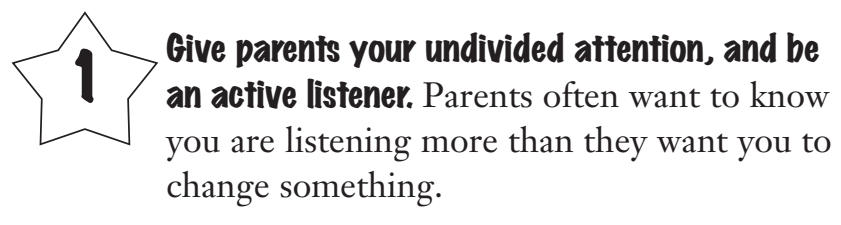

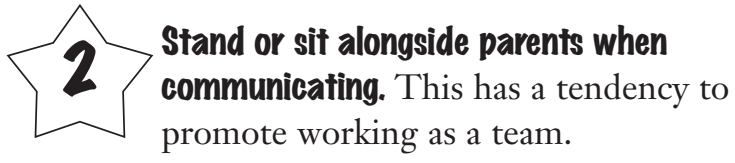

When first meeting parents, engage them in conversation and pay close attention to what they choose to discuss. Invite parents to share their goals for their child, their family's culture, history, and so on. Pay particular attention to what they report their child enjoys doing in free time as this will provide you with ideas for reinforcement; it will also immediately include parents as part of the planning team for their child.

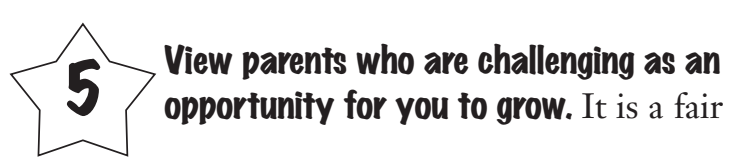


expectation of the parents that you can provide professional support for your expectations as well as your actions.

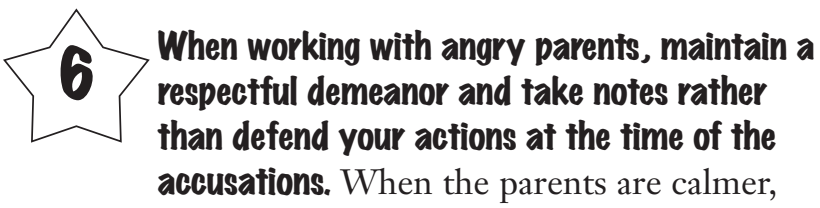
review your notes with them for accuracy but make no promises at this time. Remember that most attacks are not meant to be taken personally.

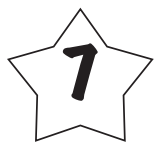

Allow parents to regard you as one of the experts in their child's education. Share your expertise and resources with them willingly and generously. For example, you may give them the address of an appropriate Web site.

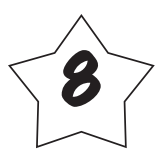
Share the relevance of the curriculum to the student's goals. Never assume parents know the "what" or "why" of school. When soliciting their support, be specific in your requests and instructions.

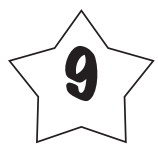
Share specific behavioral expectations early and regularly. Parents can be supportive only when they are aware of exactly what is expected.

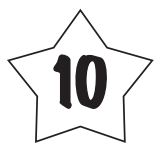

Explain that you will try to resolve any conflict their child may have at school before you engage the parents. This will be done to encourage the child to be a self-advocate.

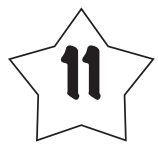
Model respect for the student by frequently acknowledging his or her efforts and achievements. A key element in doing this effectively is being specific and identifying why the effort or achievement is regarded as positive and relevant to the student's goals.

Share some of the student's positive events that happen at school, such as successfully serving on a committee. Help parents recognize the importance of celebrating the only childhood their child will have rather than focusing solely on the areas in which their child struggles.
Set up regular and frequent positive communication avenues such as a weekly newsletter that is sent home each Thursday. In the newsletter, include general and specific information regarding curriculum and activities for the past week and the upcoming week.

Be specific about when you will return phone calls, e-mails, and notes. Be consistent and reliable in honoring these scheduled times.
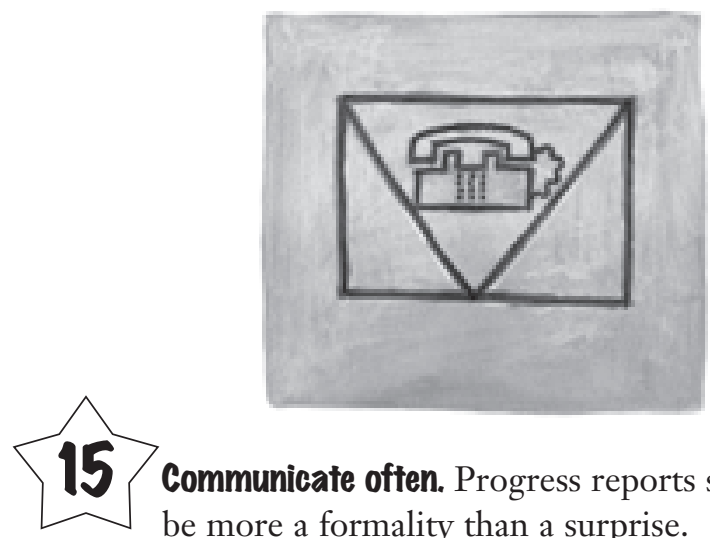

Communicate often. Progress reports should be more a formality than a surprise.

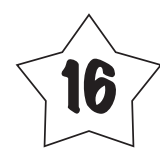

Let parents know you appreciate their support and follow-through at home. Be specific about the positive impact their effort is having on their child at school. For example, you might acknowledge the impact a daily breakfast is having on their child's energy level.

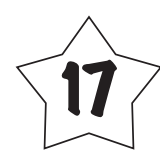
Encourage parents to make provisions for their children who do not need to be at a meeting. This allows parents to concentrate more fully on the discussions and decisions at hand.

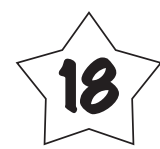
Try to have both parents present when "major" topics are being discussed. Your chance of being more fully understood is enhanced.

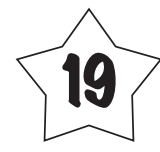

Start every meeting with a welcome, introductions, and review; clarification of the purpose of the current meeting and the ending time; and a recap of the meefing before everyone leaves. Follow up every meeting with a note that acknowledges your appreciation for the parents' input and support and a review of the results of the meeting. 


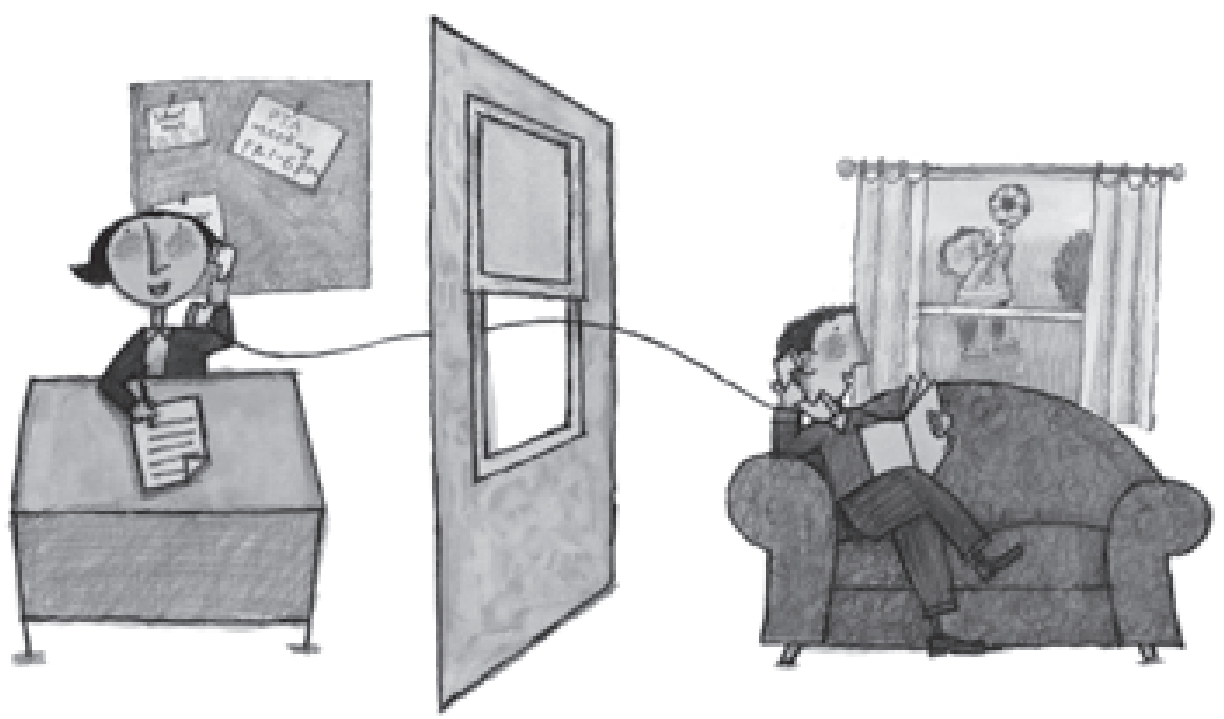

Never assume parents know how to help

with homework. Share an overview of the assignment and your expectations, as well as specific strategies for helping the child (e.g., use of rubric). The more specific you are, the greater the chance of success for the child and the parents. Try to ensure that the homework format is similar to that used in the classroom so that the experience at home is familiar to the student.

\section{About the Author}

Joyce A. Brandes, $\mathrm{PhD}$, is a lecturer in special education at the University of Oklahoma. Through her research and presentations, Dr. Brandes shares 33 years of experience in the field and classroom. She teaches classes related to understanding and ac- commodating students with exceptionalities, assessment for eligibility and program planning, and management in special education. She also serves as an instructor and supervisor for practicum and intern students. Her research interests include autism and literacy, behavior and classroom management, early intervention transition, and preservice preparation. Address: Joyce A. Brandes, University of Oklahoma, Department of Educational Psychology, 820 Van Vleet Oval, \# 302, Norman, OK 73019-2041.

\section{References}

Lucyshyn, J., Dunlap, G., \& Albin, R. W. (Eds.). (2002). Families, family life, and positive behavior support: Addressing the challenge of problem behaviors in family contexts. Baltimore: Brookes.

Shonkoff, J. P., \& Phillips, D. A. (Eds.). (2000). From neurons to neighborhoods: The science of early childhood development. Washington, DC: National Academy Press.

Webster-Stratton, C. (1998). Preventing conduct problems in Head Start children: Strengthening parenting competencies. Fournal of Consulting and Clinical Psychology, 66, 715-730. 